\title{
Quality Management In Construction Industry By Using Building Information Modelling (BIM)
}

\author{
Mr. Rohit N. Holkar ${ }^{1}$, Mrs. Smita Pataskar ${ }^{2}$ \\ ${ }^{1}$ PG Student (CM), Dr. D. Y. Patil College of Engineering, Akurdi, Pune \\ ${ }^{2}$ Assistant Professor, Dr. D. Y. Patil College of Engineering, Akurdi, Pune \\ 1rohitholkar2398@gmail.com,
}

\begin{abstract}
Building Information Modeling has the potential to help the construction sector change its design \& construction processes. While BIM is thought to assist improve design designed to remove disputes and minimising rebuilding, little study has been done on its application in projects for construct quality control \& data management. The promise of BIM implementation in quality management rests in its capacity to offer multi-dimensional data, combining design data and time sequences, due to the compatibility of project specifications using quality control processes and quality control processes. The advantages using $6 D$ BIM regarding quality framework depends upon on architectural code are examined and discussed in this study.
\end{abstract}

\section{Keywords: BIM, Modelling, Naviswork, Quality management, Revit}

\section{Introduction}

Building Information Modelling (BIM) has come to prominence as an outstandingly developed wide communitarian process and a critical area of development in the Architecture, Engineering, and Construction (AEC) sector. By incorporating BIM into development processes, you may improve the data quality needed for deciding on fundamental design decisions and determining a building's ecological impact. This research study Effectiveness of Autodesk BIM (Building Information Modelling) Innovation for quality administration just as urban masterminding of old city Infrastructure to make BIM city model and to give straightforwardness of organizations to the occupant. In perspective on brisk urbanization it ends up basic to study and plan Infrastructure of the old city, and to serve and improve the way of life of the making people, it is required to make Infrastructure of old urban systems to insightful urban systems utilizing sensible devices and Technologies, BIM Technology is One of the progression which helps for the Effective organizing, Infrastructure and rebuilding the leading body of old city and structures through various BIM Techniques like Navis work 360, Infraworks, Revit, etc.

The Construction business of India is a critical pointer of the improvement as it makes adventure openings across over various related territories. The improvement business has contributed a normal US\$ 308 billion to the national GDP in 2011-12 (a segment of around 19\%). The business is isolated, with a lot of noteworthy associations related with the improvement practices over all segments; medium-sized associations speak to impressive expert in strength activities; and little and medium legally binding specialists who tackle the subcontractor commence and finish the work in the field. In 2011, there were barely in excess of 500 improvement equipment delivering associations in the whole of India. The part is work concentrated and, including aberrant occupations, gives work to in excess of 35 million individuals 


\subsection{Objective Of Project:}

1. Determine the sector of problems arises to maintain the Quality Management on construction site.

2. To Study use of NAVISWORK for effective solutions for quality related issues on construction work.

3. Investigate the adoption and implementation of Naviswork for 'cost of quality' in construction work.

4. Evaluate the results obtained by using Naviswork for quality management

\subsection{Cost Of Quality:}

It's an often used phrase that's also commonly misinterpreted.The cost for creating a highquality product / service is not the same as the process of production a high-quality product service. That's the price of failing to provide a high-quality product or service.

The expense of quality rises with each repetition of the job. Typical instances include:

- The reworking of a manufactured item.

- The retesting of an assembly

- The rebuilding of a tool

- The correction of a bank statement

The reworking of a service, such as the reprocessing of a loan operation or the replacement of a food order in a restaurant.

\subsection{Quality Context:}

As we have seen, applying the term "quality" to the construction industry is an extremely difficult task. Quality is a vast and multiple meaning term which can be applied in many different ways to various aspects of the construction process. Figure 1 graphically outlines the contents of this study and shows the various facets of the construction process where the COQ might be analyzed, discussed and applied.

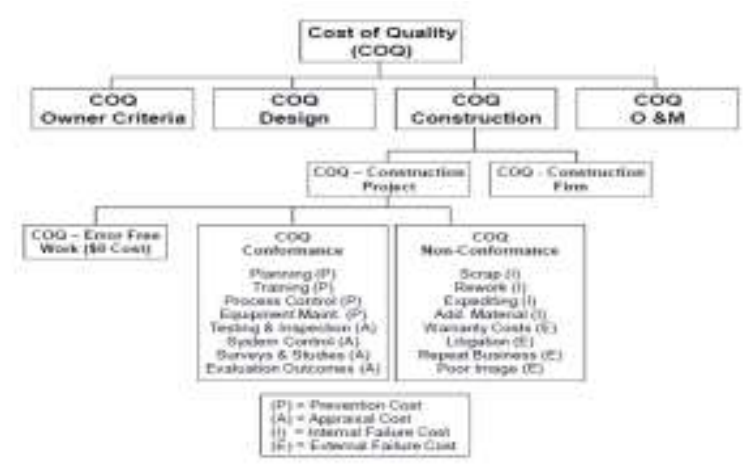

Fig No.1 Various facets of the construction process

\section{Litrature Review}

Summary: In this part a few contextual analyses; worldwide diaries are concentrated to comprehend BIM innovation. Through composing review, it very well may be assumed that BIM headway ought to be executed being created industry. The BIM progression can vanquish obstacle of standard CAD appearing.

Building Information Modeling (BIM) has changed into an uncommon grown wide communitarian process and a fundamental zone of progress in the Architecture, Engineering and Construction (AEC) industry and has risen above all solicitations. The utilization of 
BIM being created activities can develop the data quality required for picking basic system choices to get to a structure's common effect.

\section{Work Done by Researchers:}

1. Mr. Swapnesh P. Raut. Raut. Raut. Raut' Improve the Productivity of Building Construction Project using Clash disclosure Application in Building Information Modeling 2017 e-ISSN: 2395 - 0056, p-ISSN: 2395-0072, Volume: 04 Issue: 03 | Mar 2017.

In the 21st century, BIM has acquired a unique idea the Architecture, Engineering and Construction (AEC) industry, which is awards making building on a very basic level before it relies upon progress field. The beginning to execute of BIM at various levels in different made nations like USA, Australia and UK are acknowledging BIM to an inexorably unquestionable level where in India is in completed detachment to status in made nations. The Clash Detection instrument is a boss among the most obliging use of BIM, which is significant for the coordination of frameworks to affect the assignments to time productive and sparing. In this paper we center the framework included organizing conflict territory appraisal utilizing building data demonstrating programming.

2. Dr. Rula Ali Al-Damen' The effect of Total Quality Management on hierarchical execution Case of Jordan Oil Petroleum Company' Jan 2017 Vol. 8, No. 1; January 2017

This assessment expected to take a gander at the impact of TQM execution on progressive execution. The examination was driven in Jordan Petroleum Refinery Company (JPRC), the assessment test measure was (103) chairmen from different levels. The examiner depended upon fundamental and discretionary data. The results exhibit that TQM has constructive outcome on hierarchical execution. Considering these disclosures, the examination gave a course of action of proposals.

3. Tom Rajan, Anju Paul, IMPLEMENTATION OF TOTAL QUALITY MANAGEMENT (TQM) IN CONSTRUCTION-A REVIEW,2017: Vol-3 Issue-2 2017 IJARIIE-ISSN(O)- 2395-4396

Indicate quality organization or TQM is an organization rationale which revolves around incorporation of everyone and spotlights on achieving customer steadfastness. Various investigates found the impact of TQM and shows that TQM successfully influences participation satisfaction, nature of improvement adventure use, client satisfaction, and advancement adventure execution. Thinks moreover show that TQM is definitely not an overarching design and how a lot of preferences that TQM can pass on to advancement section (Improve business quality, increase purchaser reliability, lessen cost, save time and fundamentally more).

\section{Background To The Research:}

Every construction project is unique and quality is ever changing factor i.e. quality change time to time, place to place. But many common activities in construction project like the concrete work, Block work, plastering, etc. In those common works are affected by some major factors like quality of material, quality of manpower, construction detailing, etc. in this thesis following are some major factors which is affecting on quality of work. To eliminate some amount of lag in quality management can be reduced by using some modern tools like Autodesk Navisworks. It is much helpful for find out the major factors and give result with cost of poor quality. This thesis is more helpful for creating cost oriented quality awareness by using Naviswork like software for quality management of construction 
companies.

\subsection{Finance Planning:}

Money is important aspect required in any work. Finance is the main factor of construction and in every type of work. Project team had to plan for financial payment to eliminate the risk because it might affect the project. Proper financial planning is very important part to going project smoothly. Without financial planning completion of project becomes difficult task.

\subsection{Building Plan and Construction Detail:}

Problems of building plan and construction detail were found such as drawing not clear, drawing mistake, so they also became big problems in construction. Due to poor Detailing on sheets and drawings work execution becomes difficult. There are some small detailing are missing from draftsman that will become major hurdle while execution. There are lots of firms and peoples involved in Construction activity, so many detailed plans and drawing are involved in execution if the details on the drawings are not sufficient or user friendly then the work is not done as per expectation. Ultimately it will affect on the quality of work.

\subsection{Material and Equipment:}

Any construction work cannot complete without using Construction Equipment, Some construction works might use special machines or equipment which had to study carefully regarding performances, suitability for work and prepare enough equipment for each work. Construction Material requirement estimation is another important thing which has to be study because if Material required for construction activity is not estimated accurately then it might be effect on budget in future. Due to increased budget construction quality becomes secondary important thing.

\subsection{Time for completion of work:}

Completion of work with in time period is prime important thing in any construction project. In Some construction works had to be completed within a time limit such as in cases of urgent works. Some study also reported that insufficient time became a hurdle to the successful implementation of an effective quality Management.

\subsection{Co-ordination among departments:}

Coordination is very important for project successful. Because co-ordination between the departments is failed that may leads to wrong execution or may affect the sequence of work. For example consider the MEP (Mechanical Electrical Plumbing) department not properly co-ordinate with execution team, now execution team done the plastering work before plumbing works are not done due to lack of coordination. Here definitely rework required so automatically quality is misplaced.

\section{Problem Statement And Methodology Of Work :}

There are various tools and techniques are available for the quality management of construction work. Yet there are many difficulties to implement quality management in construction firms. Conventional methods of quality management are quite tedious and somehow troublesome to implement. To achieve the satisfaction of customer and quality objectives of construction firm need to use modern technologies and tools for the quality management. In this study How Naviswork like modern tool is effective for quality management is evaluating by comparative study is doing on traditional methods of quality 
management with the Naviswork modelling. For quality management and scheduling technique following case study from data collected is analyzed and compared in NAVISWORK.

Methodology of Work Flowchart

\begin{tabular}{|c|}
\hline STUDY OF QUALITY MANAGEMENT \\
\hline \\
\hline NAVISWORK STUDY \\
\hline \\
\hline DATA COLLECTION \\
\hline \\
\hline MODEL AND ANALYSIS IN NAVISWORK \\
\hline \\
\hline COMPARATIVE ANALYSIS \\
\hline \\
\hline QUESTINNAIRES SURVEY \\
\hline \\
\hline SURVEY ANALYSIS \\
\hline \\
\hline CONCLUSION \\
\hline
\end{tabular}

Fig No.2 Methodology of Work Flowchart

The goal of this study is to create a complete, informative, and useful 4D BIM-based program for construction quality control, as well as to see how it fits into the existing construction tool. Furthermore, the study highlighted possible issues with using Nevis Works technology in conjunction with existing quality control methods and suggested remedies. The quality model was used throughout the study.

Using national, industry, and municipal quality standards and regulations, include information on process, organisation, and product (POP). To define product quality criteria $\&$ responsibility assignment throughout the production process, a scheduled model or a quality model are linked it in to a virtualization 4D BIM-based application.

To demonstrate quality management, a case study method was used, which was created after a thorough examination of site research. Inspection data was received from its project construction manager, as well as CAD designs and construction schedules from its project owner \& contractors in the case study.

A G+4 proposed building of 24 flats and of 4 shops in Punawale, PUNE under PCMC for plot size 6800 sq.feet.

\section{Methodology:}

\subsection{Building Information Modeling (BIM):}

It's the procedure for generating and maintaining a digital representation of a space's physical \& functional features. BIMs (building information models) are files that may be gathered, transformed, or networked to aid in the decision-making process for a building and 
other constructed property. Individuals, companies, and government organisations utilise contemporary BIM software to plan, design, construct, manage, and operate a wide range of physical infrastructure, including water, waste, electricity, gas, communications services, highways, bridge, ports, and tunnels. Hu.

Traditional architectural design relies heavily on 2dimensional technical drawings .Modeling of Building Information The fourth size is the cost, and the fifth is the three fundamental geographical measurements . As a result, BIM encompasses more than simply geometry. It also contains spatial connections, lighting analyses, geographic data, and structural component sizes and features (e.g., manufacturer's specs).

BIM enables the development team to delegate a virtual data structure from the development team to the primary contractor and subcontractor. Owner. Each professional discipline's data is integrated under a single common model by the operator. This minimises the data loss that happens whenever a new group takes over a project and gives owners of complicated buildings with more detailed information.

\subsection{Introduction of Autodesk Navisworks:}

Autodesk NavisWorks is a reliable tool for sharing, combining, and reviewing complex 3D system design from a variety of file types. Clash detection software allows you to look for flaws in such a single model scenario when they become an issue. You can evaluate model performance \& minimise waste by using real-time visualisation and simulation. Project design, engineering, construction, \& construction experts may all be linked into an unique building or process plant model using Autodesk NavisWorks software solutions.

Overview of Architecture, Engineering \& Construction the Autodesk Navisworks software family comprises three 3D design project.

\subsection{Autodesk Navisworks Manage:}

Autodesk Navisworks Manage software is a comprehensive project review solution for design, engineering, and construction management professionals seeking powerful insight and predictability to improve productivity and quality. Autodesk Navisworks Manage software provides all the tools required for smooth-running engineering and construction projects.

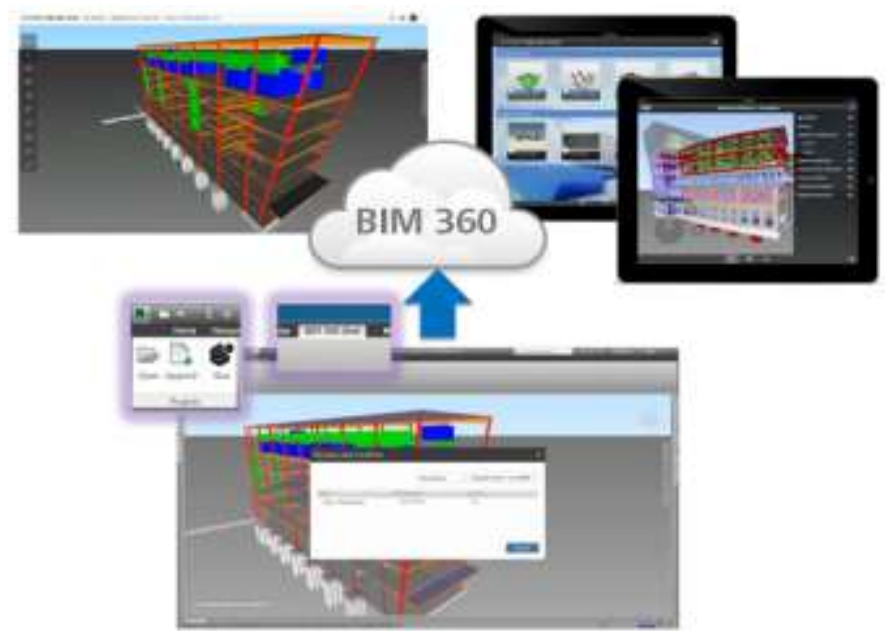

Fig.3 Navisworks Model 


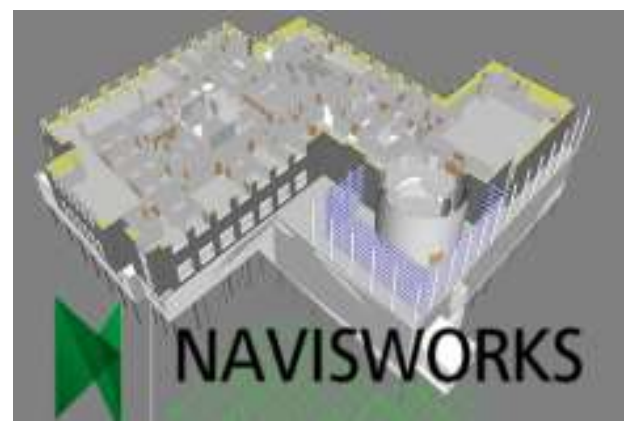

Fig.4 Naviswork Framing

\section{Key Factor To Adopt Naviswork For Quality Management}

\subsection{Faster Navigation and Checking:}

Real-time visualisation in Autodesk NavisWorks enables for quicker navigation and evaluation of complicated 3D models and the project data they contain. Manage utilising NevisWorks to discover designs quickly and easily without the need of pre-programmed animation, expensive gear, or specialised knowledge.This will help in quality management on construction site in such a way that before the execution of the work on site if project team members will go through the model they will get to know what is today's task as per scheduling and they will also get to know that which part is difficult to execute which has to emphasis while execution. Due to this number of mistakes will reduced and ultimately it will help to reduce rework hence quality will be maintained. Due to faster navigation and checking work will become easier.

\subsection{Consistent, Coordinated, Correct:}

The most comprehensive NavisWork design project review solution is provided by Autodesk NavisWorks. To Autodesk NavisWorksSimulate's dynamic 4D project schedule simulation and photorealistic visualisation, NavisWorks adds precise error-detection analysis and intervention management. Launch architectural documentation that is uniform, coordinated, and correct. The inputs given to the Navisworks are automatically linked with all the other dimensions of work like cost \& time, so no need to change all the other project values that is coordinated aspect of Naviswork which enables the project team complete their work with in time period. When you work model in Navisworks if you has maintain preciseness at the time of model designing and drafting then throw out the project it will gives you correct results. Navisworks helps companies and extended teams minimise waste, improve productivity, and decrease change orders by streamlining workflow across enterprises and extended teams.

\subsection{Clash detection:}

Detecting collisions during design, in real time, gives the team a very efficient method to improve coordination among multiple building systems and ultimately avoid costly remedies after drawing completion and during construction. Enhances ability to filter through building elements quickly and run collision tests between isolated building elements. The same filters and searches can be saved and used throughout the project. Navisworks predicts clashes by combining all of the trades in the virtual world, allowing us to revise plans and schedules to resolve conflicts before construction begins. This saves thousands of man hours that would be spent working through these issues in the field. Doing it right the first time, with a comprehensive 3D representation of the project, preserves valuable resources of time and money. 


\section{Overview of case studies:}

1. Case study of a G+4 proposed building of 24 flats and of 4 shops in Punawale, PUNE

2. Design Team : Rakesh Jain Associates

3. Owner and Developer : DipeshNavlak

4. Structural Engineer : Sushil Dateer

5. Project Manager : ShashikantNarayankar

6. Builder :Yashraj Infrapvt.ltd.

7. Area : 6800 sq.feet

8. Cost of land: $1.98 \mathrm{Cr}$.

9. Cost of construction: $2.5 \mathrm{Cr}$.

10. Area of $1 \mathrm{BHK}: 464$ square feet

11. Area of $2 \mathrm{BHK}: 800$ square feet

12. Total No. of flats

13. No. of skilled labours required: 25

14. No. of site engineer required :1

15. No. of structural engineer required $: 1$

16. No. of architect required :1

17. Location: Ravet, PCMC

18. Set back distance: 14 "

19. Side distancs-9"

20. TDR: $20 \%$

\section{Case Study:}

Drawing Shown below these are plan of plinth beam and Plumbing work. There is problem of rework and reconstruction arises on the site. First one is structural drawing provided by structural engineer and another is the plumbing drawing provided by plumbing contractor. In this case septic tank and underground water tank is placed in between plinth beams. As per the method of execution in the construction industry structural part will complete first and after that detailed work will execute but due to lack of coordination between structural engineer and plumbing contractor locations are mismatched. Due to lack of vision at the time of execution project team will not get the problem that will arising in future.

Because of the lack of vision and co-ordination plinth beam constructed over the septic tank and this is not as per plan so project team was brake beams coming across the septic tank.

As the researcher said "Quality is the result of doing the right thing and doing it right the first time on time, so as to meet the customer's expectations and needs." As per this definition of quality in above work right work is not done on right place in right timing and there is no any customer satisfaction. In short, there is no Quality work is done. 


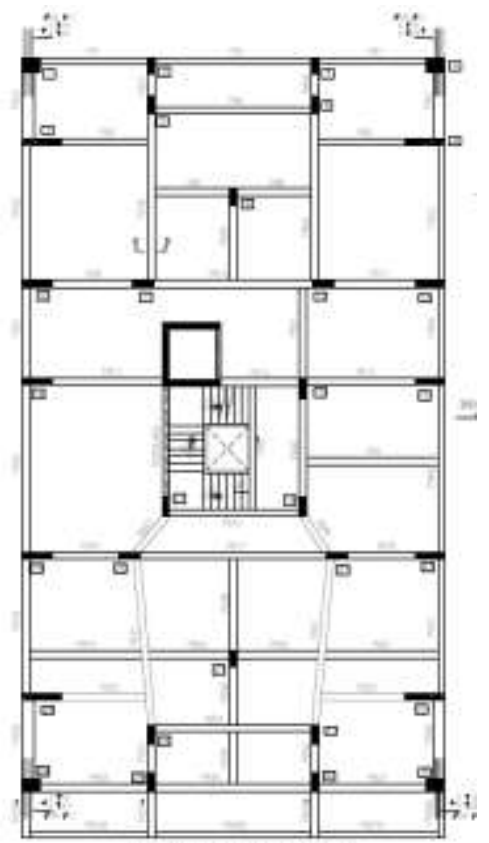

fig no 5 plinth beam framing plan

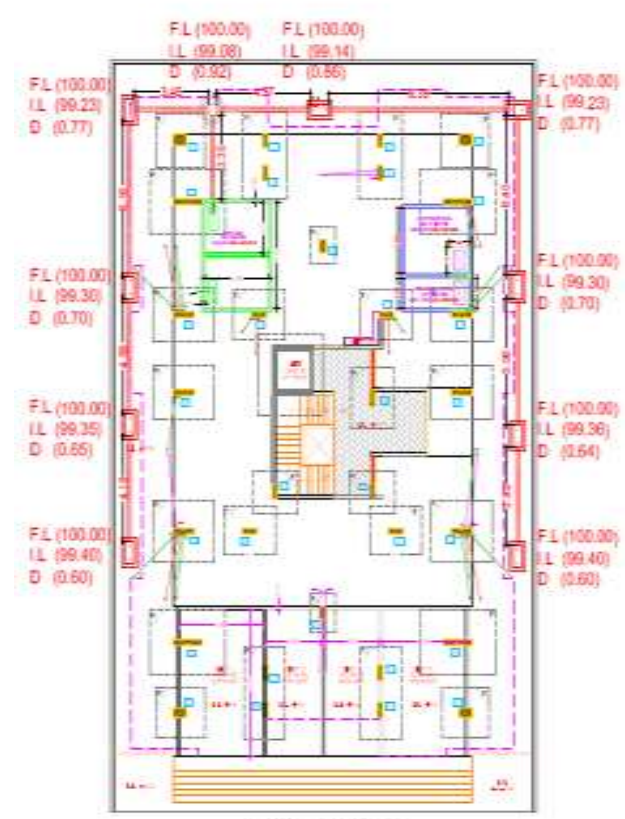

Fig. no 6 Drainage and plumbing drawing

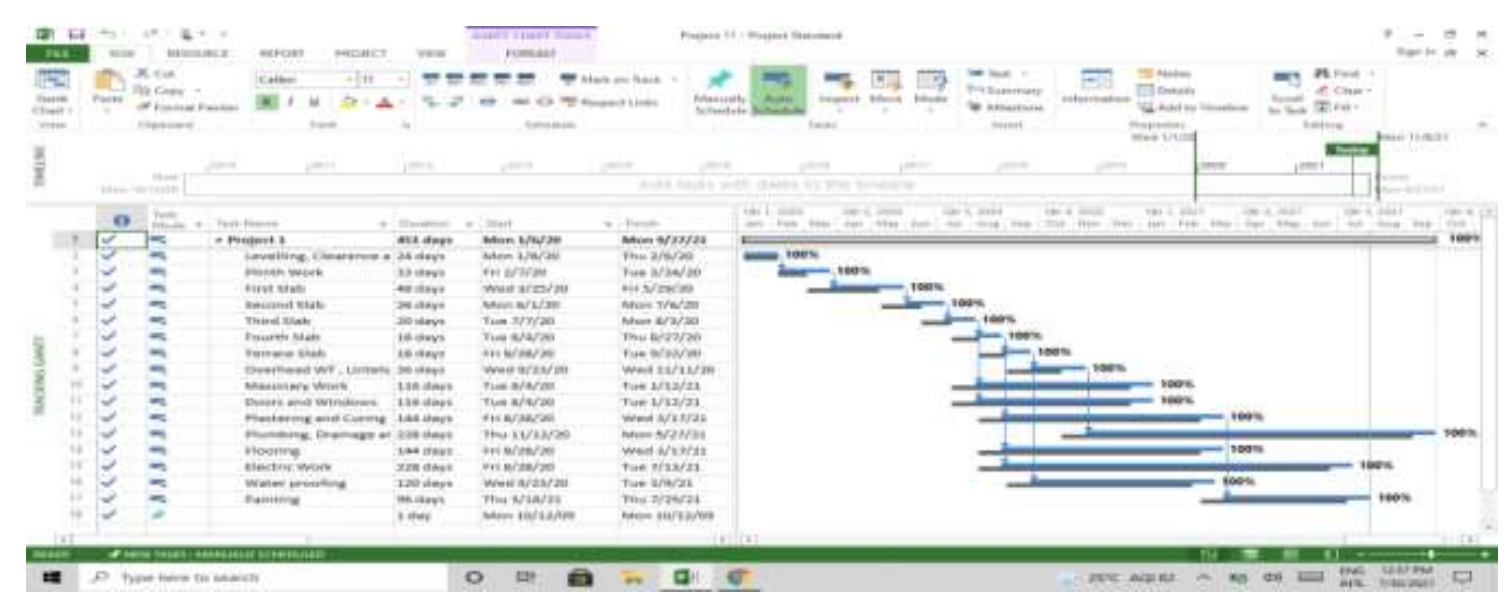

Fig no 7 MSP Schedule for site

Above figure shows schedule of site prepared in MSP. The schedule was done for 436 days.

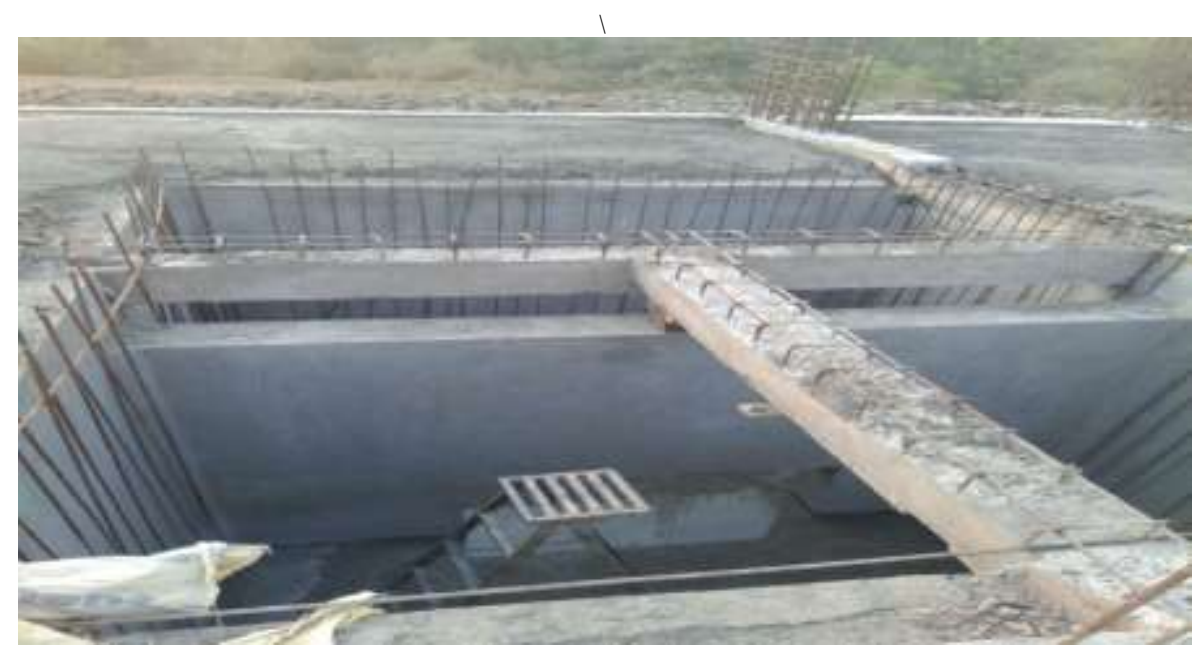

Fig 8: Photo. Plinth Beam passing through Septic Tank 


\section{Results And Discussion}

\section{Case Study:}

The above case study mentioned is analysed as a 4D BIM model in REVIT+NAVISWORKS software the two different drawings were prepared 1.plint drawing and plumbing layout including underground septic tank and underground water tank. The level difference between them was $0.3 \mathrm{~m}$.As per schedule septic tank was constructed and after that plinth beam. But due to level difference cannot be maintained the plinth beam passes through the septic tank and builder have reconstructed it. The same case can be solved in the NAVISWORKS process.

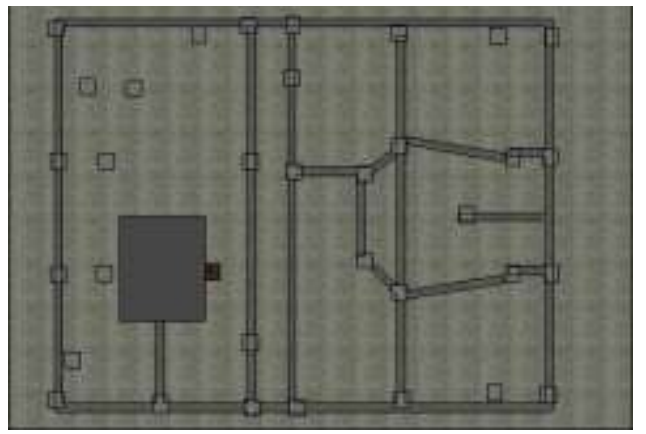

Fig 9: Model prepared in REVIT

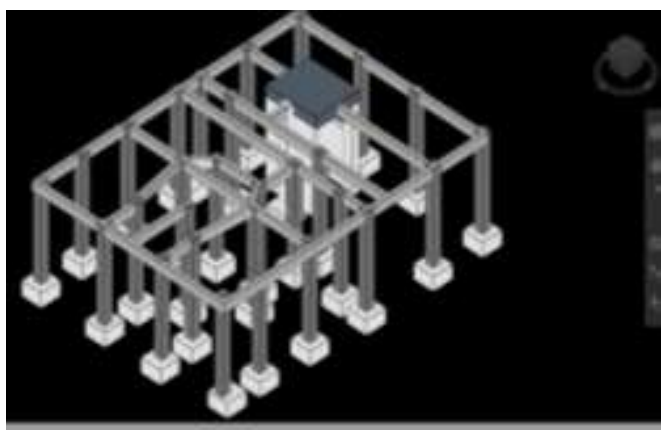

Fig 10: Model Worked in Naviswork

Results of clash detection test

Total cost expenditure on site

\begin{tabular}{|l|c|}
\hline Total days to demolish tank & 2 Days \\
\hline Total days to construct tank & 15 Days \\
\hline Total delay & 17 Days \\
\hline Direct cost & \\
\hline Total demolish cost & Rs. 4200 \\
\hline Total construction cost & Rs. $2,39,091$ \\
\hline Total Direct cost & Rs. 2,43,291 \\
\hline Indirect cost & Rs. 15000 \\
\hline Total direct and Indirect cost & Rs. 2,58,291 \\
\hline
\end{tabular}

Demolish cost- JCB $=2,200$, Transport $=1,000$, Labour $=1,000$

Indirect cost- Dewatering pump $=500 /$ day, Generator $=500 /$ day

(Above rates are taken from site) 


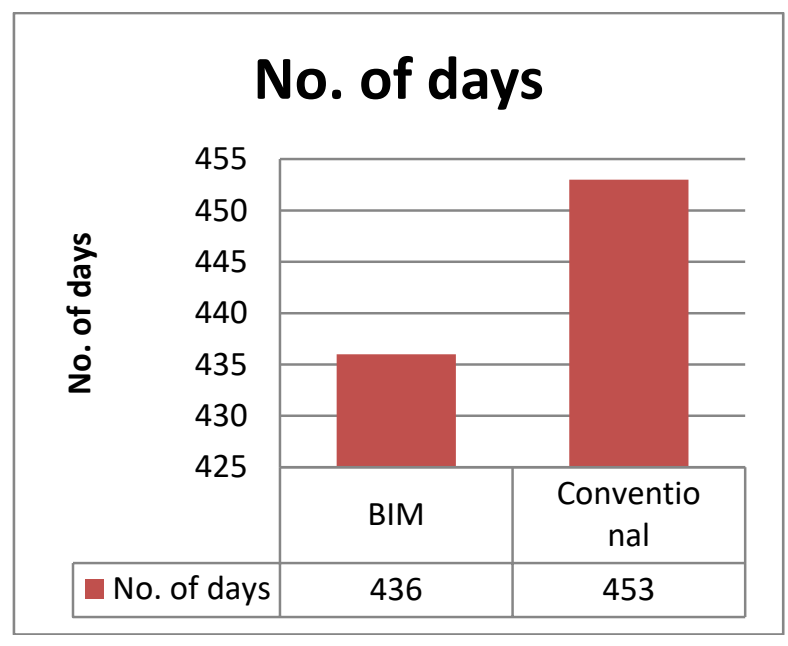

Fig 11: 4D Parameter

4D parameter is a $3 D+$ time. As we can see from above graph, number of days required for BIM is 436 days and for Conventional it is 451 days. So we can conclude that if we use BIM method, duration of project is less as compared to the conventional method.

\section{Conclusion:}

- Autodesk Naviswork is not only a visualization tool from that we can done simulation of construction site. This software can also be use for the quality Management also.

- Quality management is different from quality control. Quality control describes inspection or checking of work products. Quality management is designed to prevent defects by doing the job right. Quality management is concerned with preventing problems by creating the attitudes and environment that make prevention possible.Naviswork is done preventive work for construction site from Rework.

- In present study the quality management throughNAVISWORKS is analysed. The plinth beam and underground septic tank problem can be solved in 4D model of clash detection test total cost benefit analysis in this model was Rs. 2,58,291.

- One of the most important tasks of while using Navisworks is to effectively recognize the clashes and then group them according to their similarity so we can keep them in mind while execution and it will reduced rework and wastage of material as well as Cost, Manpower and time.

- The quality norms satisfied are setting out plan, concrete slab checking and cost of quality is maintained for this activity

- In Case study the total cost would have been saved was Rs. 2,58,291.

\section{References:}

[1] Mehmet F. Hergunsel, 'BUILDING INFORMATION MODELING FOR CONSTRUCTION MANAGERS"' May 2011

[2] P.M Diaz, 'Analysis of Benefits, Advantages and Challenges of Building Information Modelling in Construction Industry" 28 March 2016

[3] Ahmed N. El Hawary, Ayman H. Nassar, 'The Effect Of Building Information Modelling (BIM) On Construction Claims"' 12, DECEMBER 2016

[4] Nam Buiab*, Christoph Merschbrockb, Bjørn Erik Munkvolda, "A review of Building Information Modelling for construction in developing countries" 28 June 2016 :

[5] Yusuf Arayici, Charles Egbu, Paul Coates, 'Building Information Modelling (Bim) Implementation And Remote Construction Projects: Issues, Challenges, And Critiques'” May 2012

[6] Su-Ling Fan, Miroslaw J. Skibniewski, and Tsung Wei Hung, 'Effects of Building Information Modeling During Construction", 
[7] Shrikant Bhuskade’ Building Information Modeling' Volume: 02 Issue: 02 | May-2015

[8] Wenqi Zheng 'A Comprehensive Analysis of Building Information Modeling/Model (BIM) Policies in Other Countries and Its Adoption Strategies in Ontario'August 2013

[9] Dr. KihongKu'Research needs for Building Information Modeling for Construction Safety'

[10] ZoranPučko 'Building Information Modeling Based Time And Cost Planning In Construction Projects' 